Research in Social Sciences

ISSN: 2641-5305

Vol. 1, No. 2, pp. 60-68

2018

DOI: $10.53935 / 2641-5305 . v 1 i 2.9$

(C) 2018 by the authors; licensee Academic Publishing Group

\title{
Shrimp Cultivation: Development Debate and the Adverse Effect on Environment and Economy
}

\author{
Syed Ashik-E-Elahi: Department of General Education, Northern University Bangladesh. \\ *Md Ziaur Rahman: Assistant Secretary (Junior Diplomat), Ministry of Foreign Affairs, Government of the People's \\ Republic of Bangladesh.
}

Nitin Kumar: Business School, Sichuan University, Chengdu 610065, People’s Republic of China.

Jhensanam Anusara: Business School, Sichuan University, Chengdu 610065, People's Republic of China.

Bouasone Chanthamith: School of Public Administration, Sichuan University, Chengdu 610065, People's Republic of China.

Humaira Khatoon: Department of Urdu, University of Dhaka, Bangladesh.

\begin{abstract}
As an indicator of economic development, GDP remains the main factor among economists. But the hidden reality is that such parameter just shows the overall superficial economic gain but not the real development scenario of the masses. In the name of economic development, numerous degrading activities take place in the centre and periphery regions of Bangladesh. Such unplanned development activities are not only halting the natural flow of development but also creating a threat to sustainability. As the shrimp sector emerges as one of the major areas of earning foreign currency, stakeholders overlooking its multiple negative impacts on the coastal environment and traditional economic livelihood. With the introduction of shrimp cultivation different short of income sources created. As a result, some profit seekers become well off within a short period of time leaving majority unprivileged. Moreover, there is no local authority that shows any concern on the long-term suffering of the local inhabitants. In this article, we tried to show the amalgamate opinion of multiple people from different occupational groups and the conflicting areas against popular theory of development. As the research is heterogeneous in nature we used qualitative method for collecting data from various respondents. The research result clearly shows the conflicting situation and deprivation of the local inhabitants. Concluding part of this research focused on the ultimate crisis and its way out.
\end{abstract}

Key words: Shrimp cultivation, Development, Environment, Economy, Culture.

Research in Social Sciences Vol. 1, No. 2, pp. 60-68

2018

DOI: 10.53935/2641-5305.v1i2.9

Corresponding Author: Md Ziaur Rahman

Email: ziasociologydu@gmail.com

Funding: This study received no specific

financial support.

Article History:

Received: 1 October 2018

Revised: 19 October 2018

Accepted: 21 November 2018

Published: 13 December 2018

(C) 2018 by the authors; licensee Academic

Publishing Group

\section{Introduction}

Shrimp cultivation emerges in Bangladesh during sixties and it gets started on a mass production basis during nineties. The so-called blue revolution occupied the coastal water bodies of Bangladesh then. Initially shrimp cultivation started in the name of economic development and it was quite eco-friendly. Because in rotation of rice cultivation shrimp cultivated during the autumn usually. But this eco coexistence does not 
stand for long. The economic greediness of the shrimp owners changed the nature of environment friendly cultivation process. Then for more profit gain they started shrimp cultivation for the year long (Poi et al., 2018). This devastating nature of shrimp cultivation immediately destroys the local eco-system. Water bodies become saltier. As a result, local harvesting system collapsed. Moreover, local inhabitants gradually became bound to surrender their agro-based land to the shrimp cultivator or they forced to involve in shrimp cultivation. In addition, local heredity, customs and tradition lost due to the new economic and social system (Chowdhury \& Khairun, 2014).

Lebel et al. (2016) described that in Bangladesh, shrimp become one of the largest foreign exchange earning commodities, after garments and jute industries. This product is also having great importance in the international commodity business sector (Sarker et al., 2018). According to the data of fishery department in the fiscal year 2008 - 2009, the contribution of this sector in GDP is $4.57 \%$. In the same way from the data of Bangladesh Statistical Bureau, we see the wage earnings of fishery sector is 3669 in 2007 - 08 fiscal year. That is questionable regarding to my research outcome. If we look at the sector-based labor engagement then see, 48.10\% engage in agriculture, forest and fishery sector (2005-2006). That is the highest proportion employment sector of our country. If we look at the shrimp, cultivated area the data shows us 1.49-lac hectares land occupied by this sector (2008-2009). The number of hatchery for renu / pona production is 113 (public) and 873 (private) where the number of productions simultaneously 2.03 crore and 549.04 crores (2008). The percentage of landless people in rural areas is 49.3 where per head income of rural people is BDT 6096 per month.

Akber et al. (2017) mentioned that institutional arrangements for environmental protection in Bangladesh are Ministry of Environment, Forests \& Climate Change; Department of Environment; Department of Forests; Planning Commission; National Environmental Policy, 1992; National Conservation Strategy; National Environment Management Action Plan (NEMAP); Bangladesh Environmental Protection Act 1995. argued that history of the capitalist world-economy in order to address five questions (1) Development is the development of what? (2) Who or what has in fact developed? (3) What is the demand behind the demand for development? (4) How can such development occur? (5) What are the political implications of the answers to the first four questions?

Kabir et al. (2016) show the general features of coastal zone with other factors such as traditional marine, coastal and estuary fishing. He mainly focuses on shrimp Aquaculture and Coastal Afforestation. The author argued that: For quite some years now, shrimp aquaculture in brackish water has assumed importance in Bangladesh (Khan et al., 2018). It has generated income locally and has contributed significantly to the export earnings of the country. In the late fifties more than 100 paddy-cum-fish farms were reported in the present Satkhira area alone. In 1982/83, some 51.8 thousand hectares of land were under brackish water shrimp farming. By 1984/85, the area rose to an estimated 68.8 thousand acres or by about a third. The old district of Khulna alone accounts for some two-thirds of the shrimp farm acreage. At least 7 types of marine shrimps and two types of freshwater ones have potential for brackish water aquaculture of them generally the larger ones area raised in farms for export. In the south-western region, shrimp fry is stocked from December to June/July while harvesting begins from April and May continue unto October (in case of shrimp alone). KhulnaSatkhira farms are generally uniformly larger compared to others elsewhere. However, the size varies from 13 to 178 hectares. In the south-western districts he claimed the following ownership-control has been observed:

a) Single or household operation on own land.

b) Single control but with hired labor (on own rented land)

c) Many owners all or most of whom control and participate in cultivation.

d) Small number of owners and local people carry out shrimp culture on land which is partly theirs, partly rented.

e) Shrimp culture basically controlled by outsiders.

Abdullah et al. (2017) described that the foremost environmental effects of aquaculture occur because of sedimentation and obstacle of water flows, waste releases, hyper-nitrification and eutrophication, chemical remains lack of low cost quality feeds, excessive stocking density, over use of meshed feed, excessive use of medication (e.g. Antibiotics, disinfectants, pesticides etc.), use of low quality materials while producing feed, lack of proper inlet and outlet drainage systems, not following HACCP and GAP protocols, lack of waste water treatment facilities and most prominently lack of sound technical knowledge and strategies. Islam \& Yasmin (2017) mentioned that costs of prawn cultivation were reported to have increased significantly in 
recent years as a result of increased fry, feed and labor costs. The prices of both prawn fry and feed have increased dramatically since prawn farming has become widespread. Inadequate finance can therefore be a significant constraint (Prodhan et al., 2017).

From above discussion we can comprehend drastically negative impact of shrimp cultivation on the local fellow and its perpetual degradation on environment. We are talking about the gross development but never mentioned what an immense income discrimination created by it (Khan et al., 2018). A small group of people named owner of gher becoming wealthier day by day. On the other hand, a large number of people becoming poverty prone. Not only this, in the upcoming future they are going to lose their habitat for losing the natural ecosystem as the shrimp cultivation destroying land fertility. It also turns to various social and family crises for its feudal nature. With the invention of an outset group, various social problems like - drug addiction, prostitution, gambling, fornication and numbers of social problems arises. As a result, society is losing its hereditary social norms and values and, in some cases, social orders went plummet.

In this research we tried to focus on why and for what the question of development arising here. From the real scenario, we have seen instead of development social crisis and degradation arises. Finally, we showed various weaknesses of policy to meet the need of masses.

\section{Review of Related Literature}

Researchers also depicts that all the stakeholders reported that shrimp farming negatively affected on the environment at the coastal area (Nasrin et al., 2019; Sarker, et al., 2019; Sarker et al., 2019). The soil and water, fish habitation, agricultural cropland, grazing land, indigenous fish, household vegetations, trees and plants, land fertility and mangroves are affected negatively by the shrimp farming in the coastal area (Haider et al., 2015; Khan et al., 2018; Rahman et al., 2018; Islam et al., 2018; Islam et al., 2018). About 44 percent stakeholders agreed that mangroves were destroyed by the extension of shrimp farming in the study area. In the case of positive impact of shrimp farming on environment about16 percent stakeholders agreed that the household vegetations increased due to alternate rice and shrimp-prawn farming (Uzzaman, 2014). Akber et al. (2017) mentioned that Bangladesh has a large fertile tidal flooded coastal area suitable for shrimp culture. He added that lack of scientific knowledge, ownership pattern, land use conflict, institutional credit problem, security, shortage of shrimp PL, non - availability of feed and fertilizers, shrimp diseases, production management, marketing and transportation are the general problems of shrimp culture in the country. A huge number of precious aquatic organisms are being destroyed by the seed harvesters which are alarming and also a threat to natural food cycle as well. Mitro et al. (2014) explained that the extensive farming systems negatively expedite the processes: infringement of mangroves, intrusion of salinity, degradation of land, destabilization of coastal ecosystems. The major socio-economic effects challenge the patterns of livelihood pattern, displacement of family and social structure, internal migration, and livestock (Prodhan et al., 2017; Sarker \& Sultana, 2017; Sarker, 2017). The coastal regions suffer from environmental degradation due to increased salinity of soil, canals and ponds within dams, reduction in grazing field and livestock, changes in the cropping calendar and its pattern, bio-diversity (Sarker \& Sultana, 2017). Ecological aspects and sustainability are also overlooked during the shrimp cultivation. Akber et al. (2017) described that about half million coastal people are involved for shrimp seed (post larvae or fry) collection from the estuaries. Shrimp fry collection is ecologically destructive because the mesh size of the net of fry collection is very small and for this why all kinds of fishes (wanted and unwanted) are captured by the net. Bangladesh government has banned the Post Larvae (PL) collection in 2000, but the fry collectors do not obey/care the law because they are very poor and they have no other sources of income. Bangladesh government does not enforce the law maybe because of resettlement and rehabilitation cost for the shrimp fry collectors (Sarker et al., 2019; Sarker et al., 2018; Sarker et al., 2018).

As countries across the globe prepare to celebrate this annual event, Bangladesh focuses its attention on this year's theme 'Green Economy: are you included. The term green economy is no longer just a buzz word; it's a real opportunity for the world's least developed nations to embrace, if not lead the global trend into a green economy transition which in turn could lead to their accelerated development. With its rich biodiversity, economic conditions and natural and cultural assets, Bangladesh being most vulnerable to the effects of global climate change, is one of these countries (Islam et al., 2017). Ahmed et al. (2017) mentioned that the analysis reveals in particular the crucial contribution of the 'power of expertise' and shows how it has been instrumentalized by certain advocacy networks to depoliticize the debate (Sarker, 2016a). While this has

Vol. 1, No. 2, pp. 60-68

2018

DOI: $10.53935 / 2641-5305 . v 1 i 2.9$

Corresponding Author: Md Ziaur Rahman

Funding:This sudy

financial support.

Article History:

Received. I October 2018

Revised: 19 October 2018

Accepted. 21 November 2018

13 December 2018

Publishing Group

| 62 
allowed a number of key stakeholders to refocus the debate on technical solutions, it has prevented other groups concerned with more intractable social and political issues from engaging successfully in the policy process, thus leaving the long-term sustainability of aquaculture still a contentious issue (Sarker et al., 2017; Sultana, et al., 2017; Hossin et al., 2018).

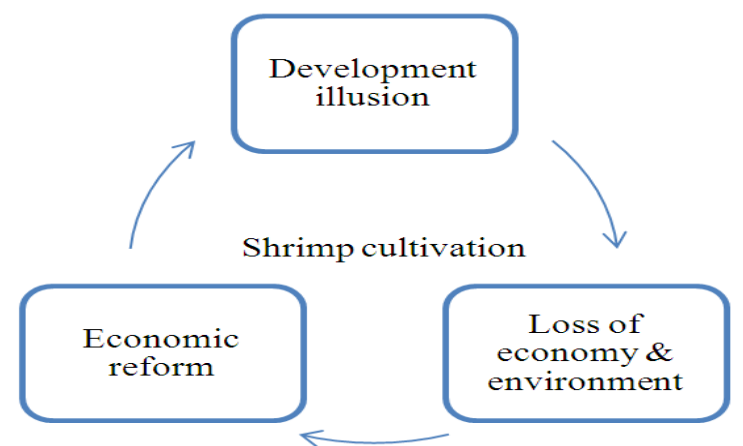

Figure-1. Conceptual framework of shrimp cultivation.

Above conceptual cycle (Figure 1) depicts the short coming diversification among income group due to shrimp cultivation. Moreover, the framework focuses on the ultimate loss of a traditional economy and loss of agricultural land.

\section{Methods of the Study}

Mainly qualitative method has been followed to pursue our research. This study was conducted through survey, life history method, participant observation and focus group discussion (FGD) on the people of selected areas of Paikgacha Thana in Khulna district.

\subsection{Sampling}

This study is very heterogeneous in nature. As a result, purposing sampling procedures were followed and the following steps were maintained. First, we selected the most significant area of our study then find out which cases are perfect for our study.

\subsection{Life History}

To fulfill the purpose, we applied Life History method focusing respondent's personal life trajectories. Through a series of interviews, the researcher can probe into the decisive moments in their life or the various influences on their life.

\subsection{Participant Observation}

This is another sort of method we have applied for our study. As the name implies, we went to the field (usually a community), lives with the people for some time, and participates in their activities in order to know and feel their culture.

\subsection{Survey Research}

We also conducted survey following a checklist to obtain necessary data. For this purpose, we conducted interviews from a set of persons chosen to represent a particular population of interest. In this survey items were open-ended.

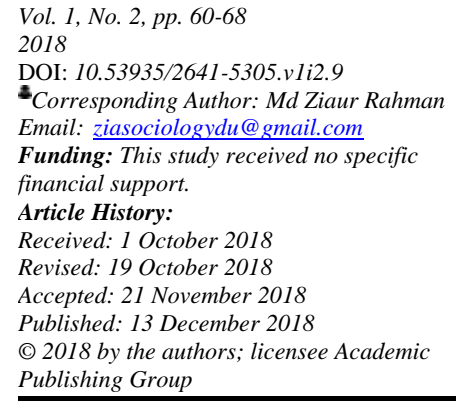

\subsection{Data Analysis}

Collected information was analyzed in a descriptive way as we followed qualitative method to conduct the study. Periodical peer review also applied in this research to get the result updated.

\section{Results}

In Paikgacha thana massive changes occurred due to extensive shrimp cultivation. Previous culture becomes memory to people. A gross infrastructural development occurs but didn't touch every level of people 
in the society (Poi et al., 2018). Moreover, the environmental loss is worth counting as most of land area lost its fertility.

At the time of collecting data from Bangladesh Fishery Research Institute Brakish Water Station, Paikgacha, Khulna; scientific officer Mr. Hindol Kumar Pal said that from their observation they had found out that this was covered by saline water from the past as it is nearer to Bay of Bengal. Though in gher area people stored saline water for the purpose of shrimp cultivation, it had no vital impact on land as it is very natural (Pousga, Magnusson, Boly, \& Ouedraogo, 2018). He also informs that at the time of rainy season sweet water covered the gher area and it make a combination with the saline land. His assessment is that it is possible to cultivate shrimp and rice in the same land and it will be beneficial for both sectors.

Reality differs with the above feedback of Hindol Kumar Pal. Because gher owners do not allow preserving rainy water in shrimp gher as it reduces the production rate of shrimp. As a result, due to more saline water paddy production is not possible in shrimp cultivated areas.

When we went to Fishery Office of Paikgacha Thana, Thana Fishery Officer Mr. shahidul Sardar told that he didn't find any problem for shrimp cultivation. He shared that shrimp cultivation not only makes people economically solvent but also creates a lot of job sectors. Those who tell that shrimp cultivation hampers the environment are not true (Boag et al., 2018).

We can reject above mentioned interview result. Because our study result shows in shrimp cultivated land saline water was logged for long. As a result saline intensity is increasing in surrounded areas of gher which is responsible for the loss of land fertility.

For instance, it is very simple to raise saline level of water in coastal areas. His argument was that shrimp cultivation didn't hamper rice cultivation rather it is possible to cultivate rice with shrimp by using HYV paddy.

\section{Comparison between Previous and Present Job Category among Inhabitants}

The figure (Figure 2) shows that drastically job nature in shrimp cultivated areas changes and it just has altered the traditional job scenario.
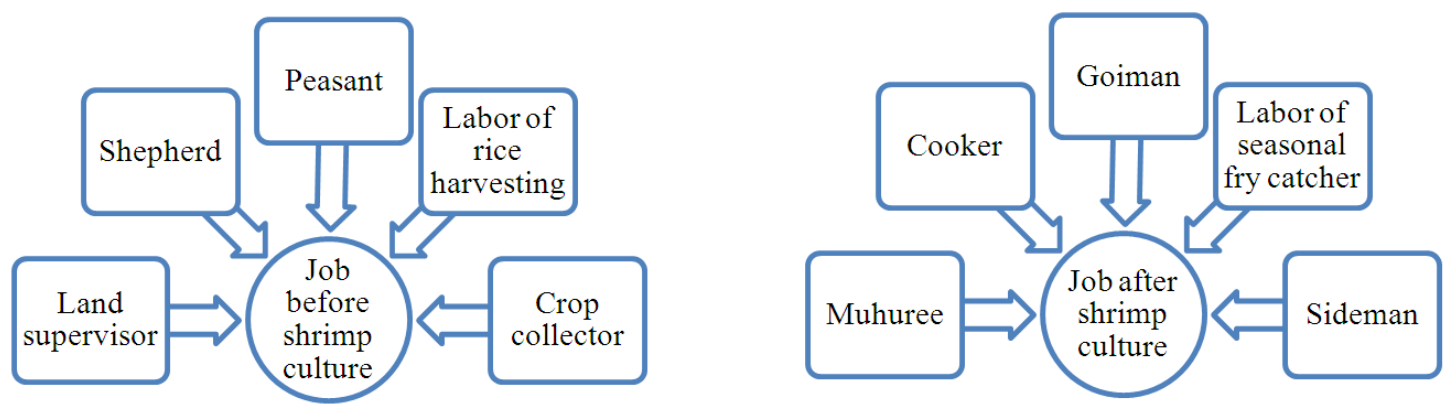

Figure-2. Drastically job nature in shrimp cultivated. Source: Field survey, 2018

It indicates that the adverse effect of shrimp cultivation from the following feedback of a well-off local respondent. Mr. Amal's life history will let us know the real-life difficulties faced by local upper-class inhabitants. There has been a significant decline in the economic position of Amal's family since 1984. This was the time from when the shrimp farming was initiated in this area on a commercial basis. Even though Amal's family has not been sub-divided, nor it disinvests any of its tangible assets yet its income earning capacity has declined drastically (Kabir et al., 2016). Amal Krishna lost on both counts. His land being saline did not yield enough paddies. Again, he lacked running capital to produce shrimp properly from the farm. Amal is very annoyed with shrimp culture. He thinks it is shrimp, which has uprooted many of the sources of livelihood (e.g. milk, ghee, fuel, vegetables, and fruits) from his homestead. He now buys some of these or his family embers learned to live without them. This shrinkage in livelihood capacity has been affecting Amal and his family socially and culturally. These days the family hardly enjoys much of the festival and social functions. The family peace has gone. Social stability has also been destroyed. The family now really loses their affiliation with mud and is not sure how long all their members will stick together in the present status. Many of them may migrate out of the village as well.

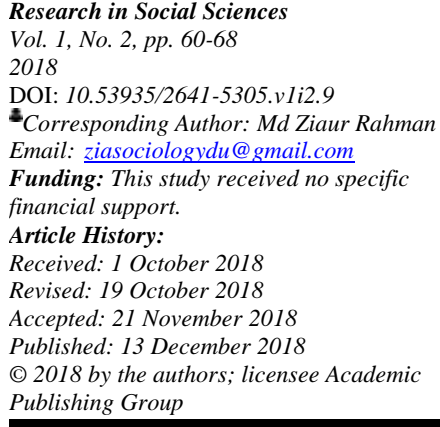


From above life history it is clearly seen that in the name of development shrimp cultivation destroyed the well-being of Amal's family. Moreover, the devastating effect of saline water intrusion and saline intensity made the agro production vulnerable. Mostly we see negative effects on local inhabitants in the name of economic advancement by shrimp culture.

Jalil has been working at Majid Sana's gher for 18 years. He gets 1800 Tk. per month as his salary. He is mainly boatman of that gher. He said his family lives at his village Mahua and he goes to home once in a month for 2 or 3 days. This is the common leave time for the worker of the gher. He said about 45 workers working at that gher. In case of any sudden crisis, they got helped from the gher proprietor. His or her salary is fixed and in Eid festival, everyone gets $300 \mathrm{Tk}$ as bonus. Besides, at the time of marriage laborer get some assistance from the owner. Jalil informed that when he first came to this gher in 1987 he saw there were trees around the gher area and besides that there were villages. Rice cultivation at that time was very high but at present in gher areas rice production become very low. Owner of the gher sometimes omit rice cultivation in gher as for this shrimp cultivation hampered (Pokrant, 2014). When he first came, he saw there were various types of birds and animals in that area but now all disappeared. The gher area becomes a separated area as the villagers around the gher go out for the lack of food and other necessaries. He said people were happy in the past time. He also said he faces a lot of problems to maintain his family with such small income in comparing with the current market price.

Above interview result shows boatman Abdul Jalil has scanty monthly salary by which he is not able to maintain his family. He seemed gloomy as he did not get enough leave to meet his family. In addition, he claimed introduction of massive shrimp cultivation destroying the fertility of soil and several species are losing due to imbalance habitat.

Bakul is working in a small gher as both worker and guard of that gher. The gher is situated in his own locality. He gets as salary $2500 \mathrm{Tk}$ per month. He said the entire locality is occupied by gher. He also informed that prior to shrimp cultivation rice cultivation was very high. In his early age, he saw green grasses occupied all around the field but nowadays it looks like desert, as there is no grassland. In his early life, he caught varieties types of birds but it is very rare now. There were fields in their village but now it is under shrimp gher. As soil becomes barren and saline water flows over it so vegetable cultivation is totally lost. For drinking water, villagers have to go seven miles away from the village. In the past people could somehow manage their everyday life but nowadays it becomes quite difficult for the lack of alternatives. Most people pass their time in idleness for the lack of work. In this area, work is seasonal. In most of the time of the whole year, they remain unemployment. He told that somehow he managed his family but in the past before introducing to shrimp culture they were quite happy.

Above interview result shows the livelihood challenges occurred due to the mass shrimp cultivation. Most importantly drinking water crisis, seasonal unemployment and loss of life saving natural ingredients have fallen badly their lives under threat.

\section{Discussion}

Information that I've collected from agriculture, fishery and from other sectors and folk oriented to shrimp cultivation shows that shrimp cultivation is extremely negative for the overall economy and environment in terms of future prospects. Besides the severe salinity, we are losing our biodiversity. However, data from fishery sectors tried to show shrimp cultivation as a positive sign but at the same time avoided the reality of violation of government rules as shrimp cultivators are breaking the polders and preserving saline water for mass cultivation of shrimp. Not only these, for more production they drain out rain water and preserve saline water for which biodiversity hampered and day by day for the immense salinity household agro production are becoming unfeasible. The crucial result is that with the mass invention of shrimp cultivation an independent social system is becoming dependent one. It is also notable that not all local landowners are interested for shrimp cultivation but the socio-political situation makes them bound to involve such business (Vivekananda et al., 2014).

Local commoners are suffering a lot as regarding the shrimp cultivation specially to ensure the supply of saline water protection of embankment management becomes vulnerable. For which cutting government made polders to ensure saline water from river source makes up thousands of gates. Finally, the result is that with scarce natural disaster like monsoon flood major part of the land boundary becomes submerged by breaking

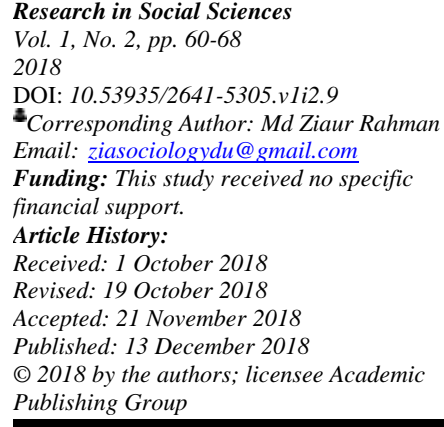


the locally made gates built for supplying saline water to shrimp gher (Sohel \& Ullah, 2012). Following tables clearly show the changing scenario.

Table-1. Annual expenses of the respondent on food \& drinking water

\begin{tabular}{|c|c|c|c|c|}
\hline \multirow{2}{*}{$\begin{array}{l}\text { Food and } \\
\text { drinking water } \\
(\text { BDT) }\end{array}$} & \multicolumn{2}{|c|}{$\begin{array}{l}\text { Cost before introducing of shrimp } \\
\text { culture }\end{array}$} & \multicolumn{2}{|c|}{$\begin{array}{l}\text { Cost after introducing of shrimp } \\
\text { culture }\end{array}$} \\
\hline & $\begin{array}{l}\text { Number } \\
\text { respondents }\end{array}$ & Percent & $\begin{array}{l}\text { Number } \\
\text { respondents }\end{array}$ & Percent \\
\hline $5000-10000$ & 31 & 44.3 & 21 & 30.0 \\
\hline $10000-20000$ & 7 & 10.0 & 17 & 24.3 \\
\hline $20000-50000$ & 14 & 20.0 & 14 & 20.0 \\
\hline $50000-100000$ & 11 & 15.7 & 18 & 25.7 \\
\hline 100000 above & 7 & 10.0 & 70 & 100.0 \\
\hline Total & 70 & 100.0 & & \\
\hline
\end{tabular}

From the above tables we can say that $44.3 \%$ of respondents said that they had to expense 5000-10000 Tk. annually for food and drinking water purposes. On the other hand, 30\% respondents said that they had to expense 5000-10000 Tk. for this purpose annually. Similarly, where 10\% respondents expend over 100000 Tk. for food and drinking purposes before introducing to shrimp culture then $25.7 \%$ respondents expend over $100000 \mathrm{Tk}$. for the same purposes after introducing shrimp cultivation. These data shows that after introducing shrimp cultivation the expenditure on food and drinking water is increased remarkably (Rahman et al., 2008). In case of social bondage, folk are losing their company with family members, as they have to stay far away for a long time for serving in a gher (Shameem \& Momtaz, 2015). Because after losing agro based job and shortage of opportunity in another field they became bound to engage in such employment opportunity related with gher. As a result, natural and social degradation are becoming the perpetual future for the local folk in the shrimp cultivated area.

\section{Conclusion and Implications}

If we compare the local scenario before and after the advent of shrimp cultivation then I can say that infrastructural development occurs but that takes place abruptly and for a small-segmented group of people. Before shrimp cultivation when agro based society prevailing, trend of development was more sustainable and ecology based. From observation, it is clear that number of brick-built household increases rather than before and transportation and communication sector were also developed. However, it is also true that with the time being all these were obvious. The basic changes in this sector I find out is that only gher owner can enjoy luxurious amenities in comparing to other fields people. Reason is that discrimination in the field of development is outspoken. For example, some owner of gher developed luxurious modern building for them. Besides, they are using luxurious cars, boats and even speed boats for their private transportation. So, in such cases they themselves took initiative to develop road, culvert or by influencing and managing government body to develop these sectors. Another cause behind such steps is easy access of transportation for their produced shrimp. Therefore, if we say ensuring lavish amenities for a small portion of people is sign of development then it is okay there. However, what is the parameter by which we can measure the destruction of a natural ecological system, eloping biodiversity, increasing barren condition of cultivable land, disrupting harmonious socio-economic livelihood and so on. In the name of development, we cannot let a harmonious community under the hand of brutal suppression.

\section{References}

Abdullah, A. N., Myers, B., Stacey, N., Zander, K. K., \& Garnett, S. T. (2017). The impact of the expansion of shrimp aquaculture on livelihoods in coastal Bangladesh. Environment, Development and Sustainability, 19(5): 20932114. Available at: https://doi.org/10.1007/s10668-016-9824-5. cultivation, mangrove deforestation and climate change in coastal Bangladesh. Marine Policy, 82(May): 68-75. Available at: https://doi.org/10.1016/j.marpol.2017.05.007.

Akber, M. A., Islam, M. A., Ahmed, M., Rahman, M. M., \& Rahman, M. R. (2017). Changes of shrimp farming in southwest coastal Bangladesh. Aquaculture International, 25(5): 1883-1899. Available at: https://doi.org/10.1007/s10499-017-0159-5. 
Boag, A. E., Hartter, J., Hamilton, L. C., Christoffersen, N. D., Stevens, F. R., Palace, M. W., \& Ducey, M. J. (2018). Climate change beliefs and forest management in eastern Oregon: implications for individual adaptive capacity. Ecology and Society, 23(4). Available at: https://doi.org/10.5751/ES-10355-230401.

Chowdhury, M. A., \& Khairun, Y. (2014). Farmers' Local Knowledge in Extensive Shrimp Farming Systems in Coastal Bangladesh. APCBEE Procedia, 8(3): 125-130. Available at: https://doi.org/10.1016/j.apcbee.2014.03.013.

Haider, M. K., Islam, M. S., Islam, S. S., \& Sarker, M. N. I. (2015). Determination of crop coefficient for transplanted Aman rice. International Journal of Natural and Social Sciences, 2(23): 34-40.

Hossin, M. A., Sarker, M. N. I., Xiaohua, Y., \& Frimpong, A. N. K. (2018). Development dimensions of e-commerce in Bangladesh. In Proceedings of the 2018 International Conference on Information Management \& Management Science - IMMS '18 (pp. 42-47). New York, New York, USA: ACM Press. Available from: https://doi.org/10.1145/3277139.3277152.

Islam, M. A., Sarker, M. N. I., Rahman, M., Sultana, A., \& Prodhan, A. S. (2017). Determinants of Profitability of Commercial Banks in Bangladesh. International Journal of Banking and Financial Law, 1(1): 1-11.

Islam, M. S., Khanam, M. S., \& Sarker, M. N. I. (2018). Health risk assessment of metals transfer from soil to the edible part of some vegetables grown in Patuakhali province of Bangladesh. Archives of Agriculture and Environmental Science, 3(2): 187-197. Available at: https://doi.org/10.26832/24566632.2018.0302013.

Islam, M. S., Proshad, R., Asadul Haque, M., Hoque, F., Hossin, M. S., \& Sarker, M. N. I. (2018). Assessment of heavy metals in foods around the industrial areas: Health hazard inference in Bangladesh. Geocarto International, 33(9): 1016-1045. Available at: https://doi.org/10.1080/10106049.2018.1516246.

Islam, M., \& Yasmin, R. (2017). The impact of Aquaculture on environment in Bangladesh. International Journal of Fisheries and Aquatic Studies, 5(4): 100-107.

Kabir, M. J., Cramb, R., Alauddin, M., \& Roth, C. (2016). Farming adaptation to environmental change in coastal Bangladesh: shrimp culture versus crop diversification. Environment, Development and Sustainability, 18(4): 1195-1216. Available at: https://doi.org/10.1007/s10668-015-9697-z.

Kabir, R., Khan, H. T. A., Ball, E., \& Caldwell, K. (2016). Climate Change Impact: The Experience of the Coastal Areas of Bangladesh Affected by Cyclones Sidr and Aila. Journal of Environmental and Public Health, 2016: 1-9. Available at: https://doi.org/10.1155/2016/9654753.

Khan, S. I., Khan, A., Sarker, M. N. I., Huda, N., Zaman, M. R., Nurullah, A., \& Rahman, M. Z. (2018). Traffic Congestion in Dhaka city: Suffering for City Dwellers and Challenges for Sustainable Development. European Journal of Social Sciences, 57(1): 116-127.

Khan, S. I., Sarker, M. N. I., Huda, N., Nurullah, A. B. M., \& Zaman, M. R. (2018). Assessment of New Urban Poverty of Vulnerable Urban Dwellers in the Context of Sub-Urbanization in Bangladesh. The Journal of Social Sciences Research, 4(10): 184-193. Available at: https://doi.org/10.32861/journal.7.410.184.183.

Lebel, L., Garden, P., Luers, A., Manuel-Navarrete, D., \& Giap, D. H. (2016). Knowledge and innovation relationships in the shrimp industry in Thailand and Mexico. Proceedings of the National Academy of Sciences, 113(17): 45854590. Available at: https://doi.org/10.1073/pnas.0900555106.

Mitro, S., Khatun, R., \& Baten, M. A. (2014). Socio-economic and environmental impacts of shrimp culture in some selected areas of Bagerhat District. Journal of Environmental Science and Natural Resources, 7(1): 265-269.

Nasrin, M., Sarker, M. N. I., \& Huda, N. (2019). Determinants of health care seeking behavior of pregnant slums dwellers in Bangladesh. Medical Science, 23(95): 35-41.

Poi, N., Sekac, T., Jana, S. K., \& Pal, D. K. (2018). Rural Development Planning - A Case Study in Developing Geospatial Data Infrastructure with the help of GIS, Remote Sensing and GPS. American Journal of Rural Development, 6(3): 59-70. Available at: https://doi.org/10.12691/ajrd-6-3-1.

Pokrant, B. (2014). Brackish Water Shrimp Farming and the Growth of Aquatic Monocultures in Coastal Bangladesh. In J. Christensen \& M. Tull (Eds.), Historical Perspectives of Fisheries Exploitation in the Indo-Pacific (Vol. 12, pp. 107-132). Available at: https://doi.org/10.1007/978-94-017-8727-7_6.

Pousga, S., Magnusson, U., Boly, H., \& Ouedraogo, G. A. (2018). Review on Biosecurity in Extensive Poultry Production in Developing Countries with Respect to Highly Pathogenic Avian Influenza, 6(3): 71-78. Available at: https://doi.org/10.12691/ajrd-6-3-2.

Prodhan, A. S., Sarker, M. N. I., Sultana, A., \& Islam, M. S. (2017). Knowledge, adoption and attitude on banana cultivation technology of the banana growers of Bangladesh. International Journal of Horticultural Science and Ornamental Plants, 3(1): 47-52.

Research in Social Sciences

2018

DOI: $10.53935 / 2641-5305 . v 1 i 2.9$

DOI: $10.53935 / 2641-5305 . v 1$ i2.9

Email: ziasociologydu@gmail.com

Funding: This study received no specific

financial support.

Article History:

Received: 1 October 2018

Revised: 19 October 2018

Accepted: 21 November 2018

Published: 13 December 2018

(C) 2018 by the authors; licensee Academic

Publishing Group

Rahman, M. M., Flitner, M., Krause, G., \& Maniruzzaman, M. (2008). Socioeconomic assessment of shrimp farming in relation to local livelihoods in the south-west coastal Bangladesh. Bangladesh Journal of Fisheries Research, 12(1): 109-120.

Rahman, M. Z., Sarker, M. N. I., Huda, N., Islam Khan, S., A. B. M., N., \& Zaman, M. R. (2018). Assessment of SocioEconomic and Sexual Vulnerability of Tea Workers in Bangladesh. The Journal of Social Sciences Research, 4(11): 229-240. Available at: https://doi.org/10.32861/jssr.411.229.240. 
Sarker, M. N. I. (2016). Causes and possible solutions of seasonal food insecurity (Monga) perceived by char dwellers in Bangladesh. International Journal of Ecology and Development Research, 1(1): 2-9.

Sarker, M. N. I. (2017). An Introduction to Agricultural Anthropology: Pathway to Sustainable Agriculture. Journal of Sociology and Anthropology, 1(1): 47-52. Available at: https://doi.org/10.12691/jsa-1-1-7.

Sarker, M. N. I., Bingxin, Y., Sultana, A., \& Prodhan, A. S. (2017). Problems and challenges of public administration in Bangladesh: pathway to sustainable development. International Journal of Public Administration and Policy Research, 3(1): 16-25.

Sarker, M. N. I., Hossin, M. A., Hua, Y., Sarkar, M. K., \& Kumar, N. (2018). Oil, Gas and Energy Business under One Belt One Road Strategic Context. Open Journal of Social Sciences, 06(04): 119-134. Available at: https://doi.org/10.4236/jss.2018.64011.

Sarker, M. N. I., \& Sultana, A. (2017). An Investigation into the Status of Riverbank (Char) Women Dwellers in Bangladesh. International Journal of Rural Development, Environment and Health Research(IJREH), 1(1): 8692.

Sarker, M. N. I., Wu, M., \& Hossin, M. A. (2018). Smart governance through bigdata: Digital transformation of public agencies. In 2018 International Conference on Artificial Intelligence and Big Data (ICAIBD) (pp. 62-70). Available from: https://doi.org/10.1109/ICAIBD.2018.8396168.

Sarker, M. N. I., Wu, M., \& Hossin, M. A. (2019). Economic Effect of School Dropout in Bangladesh. International Journal of Information and Education Technology, 9(2): 136-142. Available at: https://doi.org/10.18178/ijiet.2019.9.2.1188.

Sarker, M. N. I., Wu, M., Liu, R., \& Ma, C. (2019). Challenges and Opportunities for Information Resource Management for E-Governance in Bangladesh. In J. Xu et al. (Ed.), Proceedings ofthe Twelfth International Conference on Management Science and Engineering Management: Lecture Notes on Multidisciplinary Industrial Engineering (pp. 675-688). Springer International Publishing. Available from: https://doi.org/10.1007/978-3-319-93351153.

Sarker, N. I., Chanthamith, B., Anusara, J., Huda, N., Amin, M. Al, Jiachen, L., \& Nasrin, M. (2018). Determination of Interdisciplinary Relationship among Political Science,Social sciences and Public Administration: Perspective of Theory and Practice. Discovery, 54(273): 353-359.

Shameem, M. I., \& Momtaz, S. (2015). Local perceptions of and adaptation to climate variability and change: the case of shrimp farming communities in the coastal region of Bangladesh. Climatic Change, 133: 253-266. Available at: https://doi.org/10.1007/s10584-015-1470-7.

Sohel, M. S. I., \& Ullah, M. H. (2012). Ecohydrology: A framework for overcoming the environmental impacts of shrimp aquaculture on the coastal zone of Bangladesh. Ocean \& Coastal Management, 63: 67-78. Available at: https://doi.org/10.1016/j.ocecoaman.2012.03.014.

Sultana, A., Sarker, M. N. I., \& Prodhan, A. S. (2017). Job Satisfaction of Public and Private Primary School Teachers of Bogra District in Bangladesh. Journal of Sociology and Anthropology, 1(1): 41-46.

Uzzaman, M. A. (2014). Impact of Sea Level Rise in the Coastal Areas of Bangladesh: A Macroeconomic Analysis. Journal of Economics and Sustainable Development, 5(18): 105-110.

Vivekananda, J., Schilling, J., Mitra, S., \& Pandey, N. (2014). On shrimp, salt and security: livelihood risks and responses in South Bangladesh and East India. Environment, Development and Sustainability, 16(6): 11411161. Available at: https://doi.org/10.1007/s10668-014-9517-x.

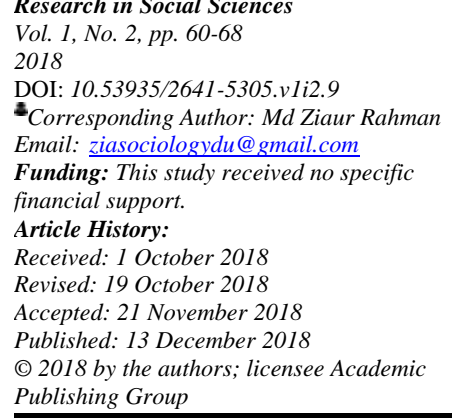

